\title{
Association between BMI, Blood Pressure, and Age: Study among Tangkhul Naga Tribal Males of Northeast India
}

\author{
N. K. Mungreiphy, ${ }^{1}$ Satwanti Kapoor, ${ }^{1}$ and Rashmi Sinha ${ }^{2}$ \\ ${ }^{1}$ Department of Anthropology, University of Delhi, New Delhi 110007, India \\ ${ }^{2}$ Faculty of Anthropology, School of Social Scinces, IGNOU, Maidan Garhi, New Delhi 110068, India
}

Correspondence should be addressed to Satwanti Kapoor, satwanti@yahoo.com

Received 8 November 2011; Accepted 6 December 2011

Academic Editor: Philipp Mitteroecker

Copyright (C) 2011 N. K. Mungreiphy et al. This is an open access article distributed under the Creative Commons Attribution License, which permits unrestricted use, distribution, and reproduction in any medium, provided the original work is properly cited.

\begin{abstract}
Purpose. To find the prevalence of overweight/obesity and hypertension, and to study the association between BMI, blood pressure, and age. Methods. Cross-sectional study was carried out among 257 Tangkhul Naga males of Northeast India, age ranging from 20-70 years. The subjects were divided into five different age groups to study age trend. Results. Mean systolic, and diastolic BP was higher among subjects with elevated BMI and among older subjects. Minimum BP was found among underweight and maximum among obese. BP was found lowest among the youngest age group and higher among the elderly subjects. BMI was also found to be associated with age independently. Although the magnitude of correlation differed, there was significant positive correlation among BMI, age, systolic and diastolic BP. Odd ratios showed overweight/obese subjects to be more likely to have hypertension than those with normal BMI. Changing socioeconomic environment intensifies the prevalence of overweight/obesity and hypertension among the Tangkhul Nagas.
\end{abstract}

\section{Introduction}

Body mass index is positively and independently associated with morbidity and mortality from hypertension, cardiovascular disease, type II diabetes mellitus, and other chronic diseases [1]. In Caucasian populations, a strong association has been depicted between BMI and mortality $[2,3]$. A similar association has also been demonstrated among Asian populations $[4,5]$.

Globally, high blood pressure is estimated to cause 7.1 million deaths, about $13 \%$ of the total. About $62 \%$ of cerebrovascular disease and $49 \%$ of ischaemic heart disease are attributable to suboptimal BP (systolic $>115 \mathrm{~mm} \mathrm{Hg}$ ). Overweight and obesity increase the risks of high BP, coronary heart disease, ischaemic stroke, type II diabetes mellitus, and certain cancers. Worldwide, about $58 \%$ of diabetes mellitus and $21 \%$ of ischaemic heart disease are attributable to BMI above $21 \mathrm{~kg} / \mathrm{m}^{2}$ [6].

In developing countries, high blood pressure is one of the risk factors for cardiovascular diseases, and the estimated 7.1 million deaths especially among middle, and old-age adults is due to high BP [6]. Developing countries are increasingly faced with the double burden of hypertension and other cardiovascular diseases, along with infection and malnutrition [7]. The relationship between BMI and BP has long been the subject of epidemiological research. Positive association BMI and BP have also been reported among Asian populations [8-10].

The burden of cardiovascular disease is high in South Asian countries, in their process of economic development [11]. Several studies indicate that high BP is associated with age and is also because of the process of modernization $[12,13]$. India in a process of rapid economic development and modernization with changing lifestyle factors has an increasing trend of hypertension, especially among the urban population [14].

Hypertension was found to be more prevalent among men than women in a study conducted among senior citizens of Delhi, India [15]. In Ethiopia and Vietnam, also hypertension was significantly more prevalent among men than women. Urban residence is the common factor in the abovementioned studies. A higher urban prevalence of hypertension was also reported in a multicentre study among elderly people in Bangladesh and India [16]. A significantly higher 
mean systolic and diastolic blood pressure among urban than rural men was reported in elderly populations of North India [17].

Around the world, traditional populations often have low blood pressure $(<120 / 80 \mathrm{~mm} \mathrm{Hg})$ and show little increase with age [18]. Similarly, in India, the traditional tribes and caste groups, which represent a substantial percent of the country's population, are believed to have lower BP than other ethnic groups [19]. Gradually, with changing social environment, marked increase in BP was noted [20]. However, few tribes and caste populations have been explored for such studies, in spite of India's diversity in terms of biological as well as sociocultural backgrounds, especially in northeastern region of India.

\section{Subjects and Methods}

A cross-sectional study was carried out among 257 Tangkhul Naga males, age ranging from 20 to 70 years. The subjects were divided into five different age groups with ten years interval each to study the age trend of height, weight, BMI, and BP. Door-to-door survey was carried out to collect data. The subjects were selected from Tangkhul villages in Ukhrul district of Maniput, Northeast India. Both the purpose of the study and techniques to be used were explained to each subject. Only those who volunteered and gave written consent were studied. All experiments were performed in accordance with relevant guidelines and regulations. The research described was compliant with basic ethical standards.

Tangkhul Naga is one of the subgroups of Naga tribe. The Nagas inhabit not only in NE India but also in the Western parts of Myanmar. The Tangkhul belongs to the Mongoloid stock and linguistically they belong to TibetoBurman language family. Tangkhul Naga is one among the major tribes of Manipur, North East India, which constitutes $19.7 \%$ of the state's total tribal population. The population of Tangkhul Naga is 146,075 and literacy rate is $72.7 \%$ [21].

Traditionally, the main source of income of the Tangkhuls was agriculture. The advent of Christianity and western education among the Tangkhuls in the later part of the 19th century played a major role in the transformation of their belief, traditional practice and education, which is the key to development and socioeconomic changes among them. With urbanization and economic development there, has been a major shif in their occupation, improvement in socioeconomic status, and lifestyle.

The staple food of the Tangkhul Nagas is rice. Most of them take lesser sweets, oily foods, and milk products when compared with the mainland Indian populations but take a lot of nonvegetarian food and leafy vegetables. Their salt intake is usually moderate. Young people often indulged in junk food and soft drinks. Nutritional transition characterized by growing intake of fat-rich diet, processed and fast food culture was observed among the subjects in younger age groups.

The Tangkhul Naga Tribe has undergone a lot of changes in the past one century in every sphere of their lives, in terms of occupation, economy, religion, traditional practices, and overall lifestyle. The socioeconomic development has created changes in dietary intake, food consumption patterns, and physical activity levels over the years. The transition has brought about nutritional transition, changes in their body composition, physiological functions, and also health among others. It has also contributed to the problem of increasing overweight/obesity and cardiovascular diseases among Tangkhul population. In the present study, an attempt has been made to find the association between body mass index, age, and blood pressure among Tangkhul Naga males of Manipur, North East India.

2.1. Assessment and Classifications of BMI and BP. For the assessment of BMI, height, and weight measurements were taken using standard protocols given by Weiner and Lourie [22]. Stature was measured by anthropometer to nearest $0.1 \mathrm{~cm}$ and weight was measured using portable spring weighing machine with least count of $0.5 \mathrm{~kg}$, in light clothing and without shoes. Standard mercury sphygmomanometer with appropriate cuff size was used to measure blood pressure. The subject was asked to sit relaxed in a chair with her/his arm supported comfortably and the pressure cuff was applied closely to the upper arm. The cuff was rapidly inflated to pressure above the level at which the radial pulse could no longer be felt. The stethoscope was placed lightly over the brachial artery and the mercury column was immediately allowed to fall at the rate of $2 \mathrm{mmHg}$ per second. The first perception of the sound was taken as the systolic pressure and then the mercury was allowed to fall further till the sound ceased to be tapping in quality, became fully muffled, and finally disappeared. The level where it disappeared was taken as the diastolic pressure. The cuff was then deflated to zero pressure. The measurement was repeated twice with five-minute interval and the average taken for accuracy.

Statistical analyses of the data collected were carried out using SPSS 10.0. Beside descriptive statistics, to test the differences between the age groups, $t$-test was done. Correlation analyses were done to determine the association between BMI, age, systolic, and diastolic BP. Multinomial logistic regression was performed to explain the impact of predictor variables in terms of odds ratios. The value of BMI was calculated and summarized age group wise, and in order to assess BMI-based nutritional status, recommended cutoff points for Asians [23] were used. Blood pressure was classified based on JNC 7 [24].

Body mass index (BMI) is calculated as the weight in kilograms divided by the square of the height in meters $\left(\mathrm{kg} / \mathrm{m}^{2}\right)$. A BMI of over $25 \mathrm{~kg} / \mathrm{m}^{2}$ is defined as overweight, and a BMI of over $30 \mathrm{~kg} / \mathrm{m}^{2}$ as obese. However, WHO advocated a lower limit of normal BMI in Asian Indians as the risk associated with diabetes and cardiovascular diseases occurs at lower levels of BMI. The WHO suggested BMI categories are as follows: $<18.5 \mathrm{~kg} / \mathrm{m}^{2}$ underweight; $18.5-23 \mathrm{~kg} / \mathrm{m}^{2}$ increasing but acceptable risk; $23-27.5 \mathrm{~kg} / \mathrm{m}^{2}$ increased risk; $\geq 27.5 \mathrm{~kg} / \mathrm{m}^{2}$ high risk [23]. In Asian subjects, the risk associated with diabetes and cardiovascular diseases occurs at lower levels of BMI when compared with the white population. This is attributed to body fat distribution; Asian 
TABLE 1: Basic data and BMI of the Tangkhul Naga males in different age groups.

\begin{tabular}{|c|c|c|c|c|c|c|c|c|c|}
\hline \multirow{2}{*}{ Age group (years) } & \multicolumn{3}{|c|}{ Stature $(\mathrm{cm})$} & \multicolumn{3}{|c|}{ Body weight (kg) } & \multicolumn{3}{|c|}{ Body mass index $\left(\mathrm{kg} / \mathrm{m}^{2}\right)$} \\
\hline & $\bar{X}$ & $\pm \mathrm{SD}$ & " $t$ " value & $\bar{X}$ & $\pm \mathrm{SD}$ & " $t$ " value & $\bar{X}$ & $\pm \mathrm{SD}$ & " $t$ " value \\
\hline $20-29$ & 164.0 & 6.16 & & 54.1 & 5.65 & & 20.1 & 1.78 & \\
\hline $30-39$ & 162.3 & 4.67 & 1.85 & 56.1 & 5.60 & $2.13^{*}$ & 21.3 & 1.93 & $3.89^{* * *}$ \\
\hline $40-49$ & 161.7 & 5.33 & .59 & 58.2 & 7.95 & 1.51 & 22.3 & 2.62 & $2.00^{*}$ \\
\hline $50-59$ & 161.6 & 5.40 & .03 & 57.5 & 10.87 & .32 & 21.9 & 3.20 & 0.48 \\
\hline $60-70$ & 156.9 & 5.35 & $3.59^{* * *}$ & 49.9 & 7.14 & $3.39^{* * *}$ & 20.3 & 2.37 & $2.39^{* *}$ \\
\hline Total & 162.0 & 5.94 & & 54.9 & 7.40 & & 20.9 & 2.39 & \\
\hline
\end{tabular}

${ }^{*} P<0.05,{ }^{* *} P<0.01,{ }^{* * *} P<0.001$.

TABLE 2: Blood pressure among Tangkhul Naga males in different age groups.

\begin{tabular}{|c|c|c|c|c|c|c|c|c|c|}
\hline \multirow{3}{*}{ Age group (years) } & \multirow{3}{*}{$N$} & \multicolumn{8}{|c|}{ Blood pressure $(\mathrm{mmHg})$} \\
\hline & & \multicolumn{4}{|c|}{ Systolic } & \multicolumn{4}{|c|}{ Diastolic } \\
\hline & & $\bar{X}$ & $\pm \mathrm{SD}$ & $\pm \mathrm{SE}$ & " $t$ " value & $\bar{X}$ & $\pm \mathrm{SD}$ & $\pm \mathrm{SE}$ & " $t$ " value \\
\hline $20-29$ & 97 & 123.7 & 13.64 & 1.39 & & 76.3 & 10.62 & 1.08 & \\
\hline $30-39$ & 58 & 125.2 & 14.36 & 1.89 & 0.64 & 81.0 & 14.49 & 1.90 & $2.32 * *$ \\
\hline $40-49$ & 35 & 126.8 & 12.95 & 2.19 & 0.55 & 84.6 & 10.44 & 1.76 & 1.28 \\
\hline $50-59$ & 32 & 125.9 & 26.00 & 4.60 & 0.19 & 83.6 & 14.93 & 2.64 & 0.32 \\
\hline $60-70$ & 35 & 134.8 & 24.57 & 4.15 & 1.45 & 80.0 & 15.32 & 2.59 & 0.99 \\
\hline Total & 257 & 126.3 & 17.69 & 1.10 & & 79.93 & 13.10 & .82 & \\
\hline
\end{tabular}

${ }^{* *} P<0.01$

Indians tend to have more visceral adipose tissue, causing higher insulin resistance, despite having lean BMI $[25,26]$.

Based on the seventh report of the Joint National Committee on Prevention, Detection, Evaluation and Treatment of High Blood Pressure [24], normal BP is define as less than $120 / 80 \mathrm{mmHg}$, prehypertension as $120-139 / 80-89 \mathrm{mmHg}$, stage I hypertension as 140-159/90-99 mmHg, and stage II hypertension as equal to and above $160 / 100 \mathrm{mmHg}$.

\section{Results}

Basic data and BMI of Tangkhul Naga males in five different age groups are displayed in Table 1 . The mean value for height was found to be highest in the youngest (20-29 years) age group. Mean height decreased in each decade in the successive age groups and lowest mean height was found among the oldest (60-70 years) age group. The differences in mean height were statistically significant only between 50 $59 \mathrm{yr}$ and 60-70 yr age groups, whereas among the rest of the groups, the differences were statistically non significant.

Body weight increased with age till the age of 49 and decreased thereafter but the differences were statistically significant only between $20-29$ yr and 30-39 yr age groups and between $50-59 \mathrm{yr}$ and $60-70 \mathrm{yr}$ age groups. Weight was found to be highest among 40-49 yr age group and lowest among 60-70 yr age group. The overall mean value of all the age groups for height and weight were $162.0 \mathrm{~cm}$ and $54.9 \mathrm{~kg}$, respectively.

Table 1 also shows BMI in different age groups. Maximum value for mean BMI was $22.3 \mathrm{~kg} / \mathrm{m}^{2}$, found among 40 $49 \mathrm{yr}$ age group. BMI was found to be lowest among 20-29 yr age group and declined thereafter. The differences in mean
TABLE 3: Distribution of subjects in different categories of BMI and BP.

\begin{tabular}{lcc}
\hline BMI and BP classifications & $\begin{array}{c}\text { Distribution of subjects in different } \\
\text { categories } \\
n\end{array}$ & $\%$ \\
\hline BMI & 37 & 14.4 \\
Underweight & 175 & 68.1 \\
Normal & 45 & 17.6 \\
Overweight/obese & 257 & 100.0 \\
\hline Total & & \\
\hline Systolic BP & 79 & 30.7 \\
Normal & 122 & 47.5 \\
Prehypertension & 41 & 16.0 \\
Hypertension stage I & 15 & 5.8 \\
Hypertension stage II & 257 & 100.0 \\
\hline Total & & \\
\hline Diastolic BP & 110 & 42.8 \\
Normal & 60 & 23.3 \\
Prehypertension & 71 & 27.6 \\
Hypertension stage I & 16 & 6.2 \\
Hypertension stage II & 257 & 100.0 \\
\hline Total & & \\
\hline
\end{tabular}

BMI was statistically significant between all the age groups except for $40-49 \mathrm{yr}$ and $50-59 \mathrm{yr}$ age groups. The mean value of all the age groups for BMI was found to be $20.9 \mathrm{~kg} / \mathrm{m}^{2}$.

Table 2 shows systolic and diastolic blood pressure in different age groups. Both the mean systolic and diastolic 
TABLE 4: Systolic and diastolic blood pressure of Tangkhul Naga males in different BMI categories.

\begin{tabular}{|c|c|c|c|c|c|c|c|c|c|}
\hline \multirow{3}{*}{\multicolumn{2}{|c|}{ BMI classifications }} & \multicolumn{8}{|c|}{ Blood pressure (mmHg) } \\
\hline & & \multicolumn{4}{|c|}{ Systolic } & \multicolumn{4}{|c|}{ Diastolic } \\
\hline & & $N$ & $\bar{X}$ & $\pm \mathrm{SD}$ & $\pm \mathrm{SE}$ & $N$ & $\bar{X}$ & $\pm \mathrm{SD}$ & $\pm \mathrm{SE}$ \\
\hline \multirow{5}{*}{ BMI } & Underweight & 37 & 116.7 & 14.07 & 2.31 & 37 & 72.4 & 10.66 & 1.75 \\
\hline & Normal & 175 & 126.8 & 15.25 & 1.15 & 175 & 79.2 & 12.62 & .95 \\
\hline & Overweight & 41 & 131.4 & 25.80 & 4.03 & 41 & 88.5 & 11.86 & 1.85 \\
\hline & Obese & 4 & 138.5 & 15.78 & 7.89 & 4 & 94.5 & 12.69 & 6.34 \\
\hline & Total & 257 & 126.3 & 17.69 & 1.10 & 257 & 79.9 & 13.10 & .82 \\
\hline
\end{tabular}

TABLE 5: Correlation matrix between BMI, blood pressure, and age.

\begin{tabular}{lcccc}
\hline \multirow{2}{*}{ Variables } & \multicolumn{4}{c}{ Correlation between BMI and BP } \\
& BMI & Systolic BP & Diastolic BP & Age \\
\hline BMI & 1.000 & $.274^{* *}$ & $.378^{* *}$ & $.127^{*}$ \\
Systolic BP & $.274^{* *}$ & 1.000 & $.597^{* *}$ & $.181^{* *}$ \\
Diastolic BP & $.378^{* *}$ & $.597^{* *}$ & 1.000 & $.167^{* *}$ \\
Age & $.127^{*}$ & $.181^{* *}$ & $.167^{* *}$ & 1.000 \\
\hline
\end{tabular}

Correlation is significant at the ${ }^{* *} 0.01$ level (2-tailed); ${ }^{*} 0.05$ level (2-tailed).

BP were found to be lowest among the youngest age groups. Systolic BP increased steadily with age and the highest was found among the oldest age group. The differences in mean systolic BP between different age groups were statistically nonsignificant. Diastolic BP increased with age till 40-49 yr and declined thereafter but the differences in mean BP between age groups were statistically nonsignificant with the exception of 20-29 yr and 30-39 yr age groups.

Table 3 displays the distribution of subjects in different categories of BMI and BP. Maximum numbers of subjects were in normal BMI category (68\%) followed by those in overweight/obese category (17.6\%). Lowest numbers of subjects were found in underweight $(14.4 \%)$ category. As assessed from systolic blood pressure, maximum numbers of subjects were in prehypertension (47\%) stage followed by those with normal (30.7\%) systolic BP. Diastolic BP showed maximum subjects to have normal $(42.8 \%)$ BP followed by those in prehypertension (23.3\%). There were sizeable numbers of stage I hypertensive subjects as assessed from both systolic (16\%) and diastolic (27.6\%) blood pressure among Tangkhul Naga males. There were also 5.8\% and 6.2\% stage II hypertensive subjects as assessed from systolic and diastolic blood pressure respectively.

Table 4 displays the value of systolic and diastolic BP in different BMI categories. Minimum mean systolic and diastolic BP were found in underweight category and the maximum systolic and diastolic BP were found among obese category. The mean values of both the systolic and diastolic BP increased from underweight to normal and then to overweight and obese category. It showed that mean systolic and diastolic BP increased with increasing BMI level.

Correlation between BMI, BP, and age with level of significance given in Table 5. There were significant $(P<$ $0.01)$ positive correlations of BMI with both systolic and diastolic BP. It showed that BP increased with increase in
BMI. Correlation coefficient showed that relationship of BMI with diastolic BP (0.378) was stronger than systolic BP (0.274). There was also significant $(P<0.05)$ positive correlation between age and BMI, but the magnitude of correlation of age with systolic and diastolic BP $(P<0.01)$ was more than that of age with BMI.

Table 6 displays the odds ratio for predicting systolic and diastolic blood pressure. Multinomial logistic regression was applied for predicting systolic and diastolic BP using BMI as the independent variable. As assessed from systolic blood pressure, it showed that those who were overweight/obese $\left(\mathrm{BMI} \geq 23 \mathrm{~kg} / \mathrm{m}^{2}\right)$ were 1.47 times more likely to have prehypertension, 2.42 times more likely to have stage I hypertension, and 4.78 times more likely to have stage II hypertension than those who were in normal BMI category. Assessing from diastolic blood pressure showed that those who were overweight/obese $\left(B M I \geq 23 \mathrm{~kg} / \mathrm{m}^{2}\right)$ were 2.49 times more likely to have prehypertension, 3.76 times more likely to have stage I hypertension, and 7.39 times more likely to have stage II hypertension than those who were in normal BMI category. Those who were underweight (BMI $<18.5 \mathrm{~kg} / \mathrm{m}^{2}$ ) were less likely to have higher systolic and diastolic blood pressure than those who were in normal BMI category.

\section{Discussion}

Increasing secular trend in the mean stature was evident from the oldest to the youngest age groups. Improvement in socioeconomic conditions, and better nutrition among the younger subjects could be the reason. The reason for decline in stature in advanced age could also be due to thinning of intervertebral discs as well as flabbiness of muscles, which changes the posture. Aiken [27] reported that a loss of collagen between spinal vertebrae causes the spine to bow and the height to shrink. Similar findings have been reported by Kapoor and Tyagi [28] and Bhardwaj and Kapoor [29].

The Tangkhul Nagas were small and slender in comparison to the mainland Indian or the western populations. Body weight increased with age till the age of 49 years and slightly decreased after 50 years. The increase in body weight and BMI with age and decline in advanced age has also been reported by Kapoor and Tyagi [28] and Tandon [10]. Increase in body weight till middle age may be due to the accumulation of fat with age as the younger subjects have larger appetite leading to increased energy intake, fatrich diet, and relatively less energy expenditure due to lesser 
TABLE 6: BMI as a risk factor for systolic and diastolic blood pressure.

\begin{tabular}{|c|c|c|c|c|c|c|}
\hline \multirow{3}{*}{ BMI classifications } & \multicolumn{6}{|c|}{ Odds ratio } \\
\hline & \multicolumn{3}{|c|}{ Systolic blood pressure } & \multicolumn{3}{|c|}{ Diastolic blood pressure } \\
\hline & Prehypertension & $\begin{array}{l}\text { Hypertension } \\
\text { Stage I }\end{array}$ & $\begin{array}{c}\text { Hypertension } \\
\text { Stage II }\end{array}$ & Prehypertension & $\begin{array}{c}\text { Hypertension } \\
\text { Stage I }\end{array}$ & $\begin{array}{c}\text { Hypertension } \\
\text { Stage II }\end{array}$ \\
\hline Overweight/obese & 1.47 & 2.42 & 4.78 & 2.49 & 3.76 & 7.39 \\
\hline Underweight & -0.44 & -0.09 & -0.32 & -0.49 & -0.24 & -0.12 \\
\hline Normal BMI & $\mathrm{a}$ & $\mathrm{a}$ & $\mathrm{a}$ & $\mathrm{a}$ & $\mathrm{a}$ & $\mathrm{a}$ \\
\hline
\end{tabular}

$\mathrm{a}=$ Reference category (Normal Categories).

involvement in physical activities. The decline in body weight in more advanced age may be attributed to the decrease in muscle mass in response to reduced amount of protein intake as well as decline in number and size of muscle fibers due to degenerative diseases associated with the advancing age. It may partly be due to bones becoming lighter because of gradual mineral mass loss [30].

Age was positively correlated with BMI and both systolic and diastolic BP. Systolic and diastolic blood pressures increased with age steadily from the youngest to the oldest age group showing the dependence of BP on age. Earlier studies also indicated that high BP is associated with age [13, $31,32]$. In the present study, association of age with systolic and diastolic blood pressures was stronger than that of age with BMI. Thus, the association of systolic and diastolic BP with age was more significant than that of BMI with age. Blood pressure was higher in the elderly strata of the sample with or without a corresponding elevation in BMI suggesting the involvement of some other contributory factors also for hypertension besides fats accumulation alone. A significant correlation between BP and age was also reported in a study from North India [33].

Correlation analyses between BMI and BP showed significant positive correlations between them. When the mean systolic and diastolic blood pressures among different BMI categories were evaluated, it was found that mean systolic and diastolic blood pressure increased with increasing BMI from lowest BMI to the highest BMI category. Both systolic and diastolic BP increased with increase in BMI level. In a study conducted among Punjabi girls of Delhi, a significant correlation of BMI with blood pressure was also found [9]. Positive associations between BMI and BP have also been reported in other Indian populations $[8,10]$.

The present study showed BMI as strong predictor of blood pressure. Kumanyika et al. [34] have shown body mass index to be even more strongly related than race to blood pressure and that its effect is similar across surveys in the United State and within sex and racial groups. A number of investigators have concluded that among many relevant factors, body mass index is one of the most important predictors of blood pressure. Although ethnicity and genetics have long been known to influence the distribution of blood pressure levels within a population, these factors seem to have less bearing on the difference in blood pressure levels between populations [35].

Odds ratio showed that BMI is a significant predictor of high systolic and diastolic BP. Similar findings have been reported in other studies [10, 33, 36]. Underweight subjects were less likely to have high blood pressure than those who were in normal BMI category. Overweight or obese subjects were more likely to have significantly higher blood pressure than those with normal BMI in all the three stages of prehypertension, stage I hypertension, and stage II hypertension. In the present study, multinomial logistic regression analysis identified overweight and obesity as significant determinants of hypertension among Tangkhul Naga males.

\section{Conclusion}

The study demonstrated that body mass index is closely associated with both systolic and diastolic blood pressure among the Tangkhul Naga males. BP is also associated with rising age independently. Though the magnitude of correlation differed, there was positive and significant correlation among BMI, age, systolic and diastolic blood pressures. Mean systolic and diastolic BP levels were higher among subjects with elevated BMI. The risk of hypertension was higher among population groups who were overweight or obese. There were sizable numbers of hypertensive subjects, especially in stage I. Although traditional populations around the world were often believed to have low blood pressure, gradually with changing socioeconomic environment, marked increase in blood pressure and overweight or obesity level has been noted as was evident from the present study among the Tangkhul Naga Tribal Males.

\section{Acknowledgments}

The authors are thankful to all the subjects. N. K. Mungreiphy is grateful to the University Grants Commission (UGC) for providing financial assistance through RGNF.

\section{References}

[1] F. X. Pi-Sunyer, "Medical hazards of obesity," Annals of Internal Medicine, vol. 119, no. 7, pp. 655-660, 1993.

[2] M. D. A. F. Hoffmans, D. Kromhout, and C. De Lezenne Coulander, "The impact of body mass index of 78,612 18-year old Dutch men on 32-year mortality from all causes," Journal of Clinical Epidemiology, vol. 41, no. 8, pp. 749-756, 1988.

[3] J. Stevens, J. Cai, E. R. Pamuk, D. F. Williamson, M. J. Thun, and J. L. Wood, "The effect of age on the association between body-mass index and mortality," New England Journal of Medicine, vol. 338, no. 1, pp. 1-7, 1998. 
[4] C. Ni Mhurchu, A. Rodgers, W. H. Pan et al., "Body mass index and cardiovascular disease in the Asia-Pacific Region: an overview of 33 cohorts involving 310000 participants," International Journal of Epidemiology, vol. 33, no. 4, pp. 751$758,2004$.

[5] X. Weng, Y. Liu, J. Ma, W. Wang, G. Yang, and B. Caballero, "Use of body mass index to identify obesity-related metabolic disorders in the Chinese population," European Journal of Clinical Nutrition, vol. 60, no. 8, pp. 931-937, 2006.

[6] World Health Organization, "Reducing risks, Promoting Healthy Life," type, World Health Report, Geneva, Switzerland, 2002.

[7] C. J. L. Murray and A. D. Lopez, Global Health Statistics. Global Burden of Disease and Injury Series, Harvard School of Public Health, Boston, Mass, USA, 1996.

[8] R. Gupta, S. Guptha, V. P. Gupta, and H. Prakash, "Prevalence and determinants of hypertension in the urban population of Jaipur in western India," Journal of Hypertension, vol. 13, no. 10, pp. 1193-1200, 1995.

[9] S. S. Kapoor, "Blood pressure, waist to hip ratio and body mass index among affluent Punjabi girls of Delhi," Acta Medica Auxologica, vol. 32, no. 3, pp. 153-157, 2000.

[10] K. Tandon, Obesity, its distribution pattern and health implications among Khatri population, Ph.D. thesis, Department of Anthropology, University of Delhi, Delhi, India, 2006.

[11] S. Nishtar, "Prevention of coronary heart disease in south Asia," Lancet, vol. 360, no. 9338, pp. 1015-1018, 2002.

[12] N. K. Mungreiphy and S. Kapoor, "Emerging epidemic of obesity: health consequences, assessment and its implications," in Obesity: A Multidimensional Approach to Contemporary Global Issue, R. Sinha and S. Kapoor, Eds., pp. 208-221, Dhanraj Book House, New Delhi, India, 2009.

[13] J. I. Schall, "Sex differences in the response of blood pressure to modernization," American Journal of Human Biology, vol. 7, pp. 159-172, 1995.

[14] R. Gupta, "Trends in hypertension epidemiology in India," Journal of Human Hypertension, vol. 18, no. 2, pp. 73-78, 2004.

[15] R. Tyagi and S. Kapoor, "Ageing in structural and functional dimensions among institutionalized and noninstitutionalized senior citizens," Anthropologie, vol. 42, no. 2, pp. 141-146, 2004.

[16] I. Quasem, M. S. Shetye, S. C. Alex et al., "Prevalence, awareness, treatment and control of hypertension among the elderly in Bangladesh and India: a multicentre study," Bulletin of the World Health Organization, vol. 79, no. 6, pp. 490-500, 2001.

[17] P. Bovet, A. G. Ross, J. P. Gervasoni et al., "Distribution of blood pressure, body mass index and smoking habits in the urban population of Dar es Salaam, Tanzania, and associations with socioeconomic status," International Journal of Epidemiology, vol. 31, no. 1, pp. 240-247, 2002.

[18] W. W. Dressler, "Modernization, stress, and blood pressure: new directions in research," Human Biology, vol. 71, no. 4, pp. 583-605, 1999.

[19] Y. S. Kusuma, B. V. Babu, and J. M. Naidu, "Blood pressure levels among cross-cultural populations of Visakhapatnam district, Andhra Pradesh, India," Annals of Human Biology, vol. 29, no. 5, pp. 502-512, 2002.

[20] A. Nirmala, "Age variation in blood pressure: effect of sex and urbanization in a genetically homogeneous caste population of Andhra Pradesh," American Journal of Human Biology, vol. 13, no. 6, pp. 744-752, 2001.

[21] Census of India, 2001, http://www.censusindia.gov.in/.
[22] J. S. Weiner and J. A. Lourie, Practical Human Biology, Academic Press, London, UK, 1981.

[23] C. Barba, T. Cavalli-Sforza, J. Cutter et al., "Appropriate bodymass index for Asian populations and its implications for policy and intervention strategies," Lancet, vol. 363, no. 9403, pp. 157-163, 2004, Erratum in: Lancet, vol. 363, no. 9412, p. 902, 2004.

[24] JNC 7, "The seventh report of the joint national committee on prevention, detection, evaluation, and treatment of high blood pressure," Journal of the American Medical Association, vol. 289, pp. 2560-2571, 2003.

[25] M. A. Banerji, N. Faridi, R. Atluri, R. L. Chaiken, and H. E. Lebovitz, "Body composition, visceral fat, leptin, and insulin resistance in Asian Indian men," Journal of Clinical Endocrinology and Metabolism, vol. 84, no. 1, pp. 137-144, 1999.

[26] M. Chandalia, N. Abate, A. Garg, J. Stray-Gundersen, and S. M. Grundy, "Relationship between generalized and upper body obesity to insulin resistance in Asian Indian men," Journal of Clinical Endocrinology and Metabolism, vol. 84, no. 7, pp. 2329-2335, 1999.

[27] L. R. Aiken, Aging: An Introduction to Gerontology, SAGE, New York, NY, USA, 1995.

[28] S. Kapoor and S. Tyagi, "Fatness, fat patterns and changing body dimensions with age in adult males of a high altitude population," in Science of Man in the service of Man, M. K. Bhasin and S. L. Malik, Eds., vol. 8, pp. 129-136, 2002.

[29] S. Bhardwaj and S. Kapoor, "Nutritional anthropometry and health status: a study among Dhanka tribals of Rajasthan," Anthropologist, vol. 9, no. 3, pp. 211-214, 2007.

[30] S. Verma, S. Kapoor, and I. P. Singh, "A study of age changes in physical fitness (as measured by rapid fitness index) and its relationship with other body measurements among Lodha tribals of West Bengal," Indian Anthropologist, vol. 17, pp. 101108, 1987.

[31] W. W. Dressler and J. R. Bindon, "Social status, social context, and arterial blood pressure," American Journal of Physical Anthropology, vol. 85, no. 18, p. 82, 1994.

[32] V. Suman and S. Kapoor, "Effect of cold stimulus on blood pressure," in Contemporary Studies in Human Ecology: Human Factor, Resource Management and Development, M. K. Bhasin and S. L. Malik, Eds., pp. 349-354, Kamle Raj Enterprises, 1998.

[33] R. B. Singh, S. S. Rastogi, V. Rastogi et al., "Blood pressure trends, plasma insulin levels and risk factors in rural and urban elderly populations of north India," Coronary Artery Disease, vol. 8, no. 7, pp. 463-468, 1997.

[34] S. K. Kumanyika, J. R. Landis, Y. L. Matthews, S. L. Weaver, L. C. Harlan, and W. R. Harlan, "Secular trends in blood pressure among adult blacks and whites aged 18-34 years in two body mass index strata, United States, 1960-1980," American Journal of Epidemiology, vol. 139, no. 2, pp. 141-154, 1994.

[35] A. G. Shaper and P. H. Whincup, "Annotation: hypertension in populations of African origin," American Journal of Public Health, vol. 87, no. 2, pp. 155-156, 1997.

[36] E. S. Rosmarakis, P. I. Vergidis, E. S. Soteriades, K. Paraschakis, P. A. Papastamataki, and M. E. Falagas, "Estimates of global production in cardiovascular diseases research," International Journal of Cardiology, vol. 100, no. 3, pp. 443-449, 2005. 


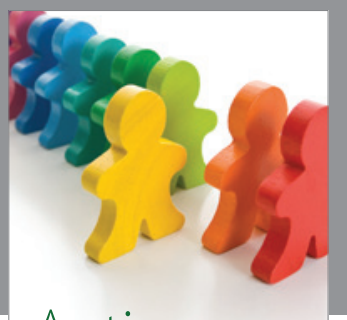

Autism

Research and Treatment
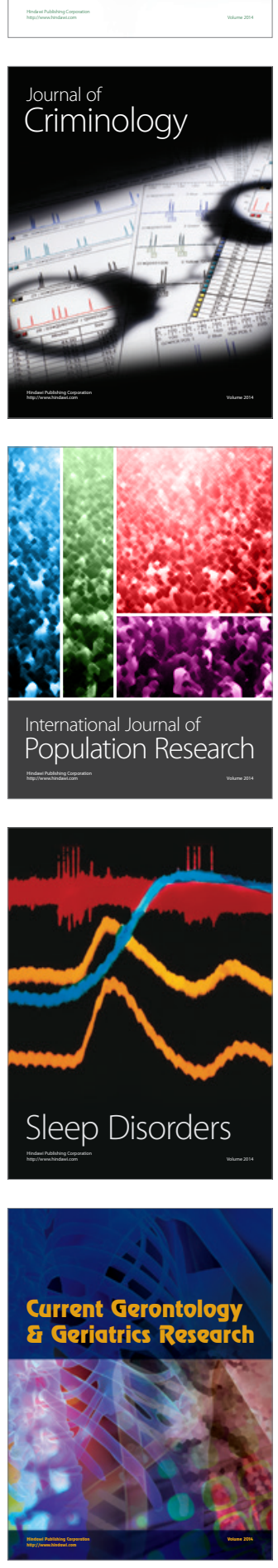
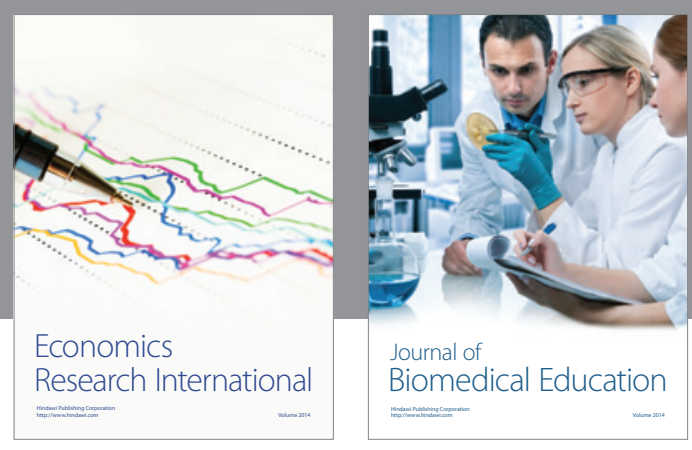

Journal of

Biomedical Education

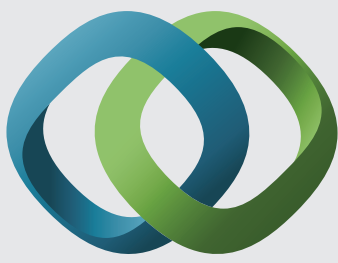

\section{Hindawi}

Submit your manuscripts at

http://www.hindawi.com
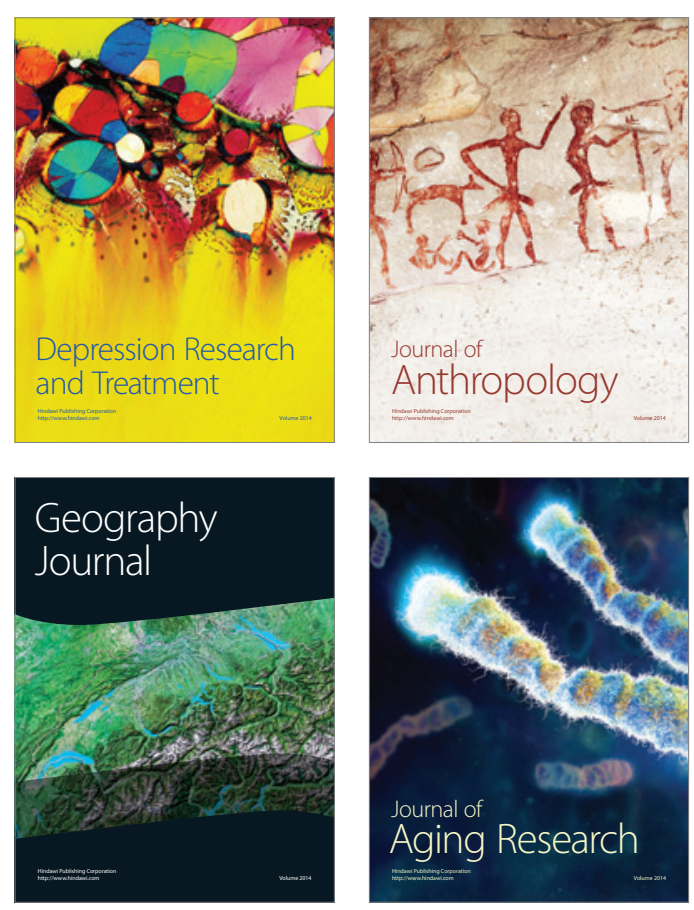

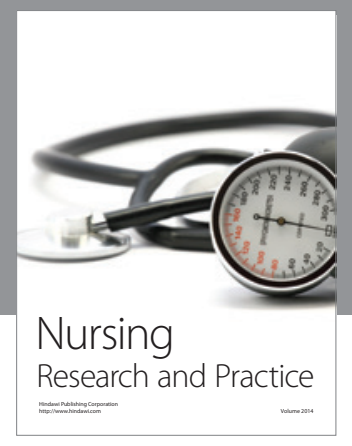

Nursing

Research and Practice

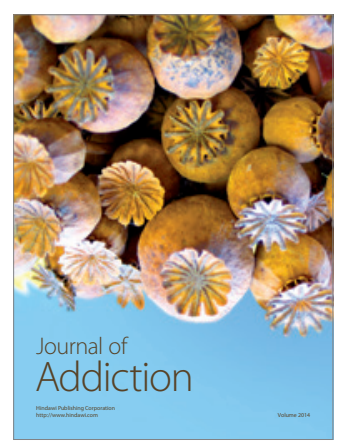

Child Development

Research

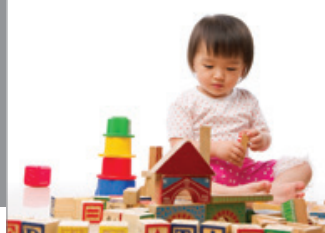

迥
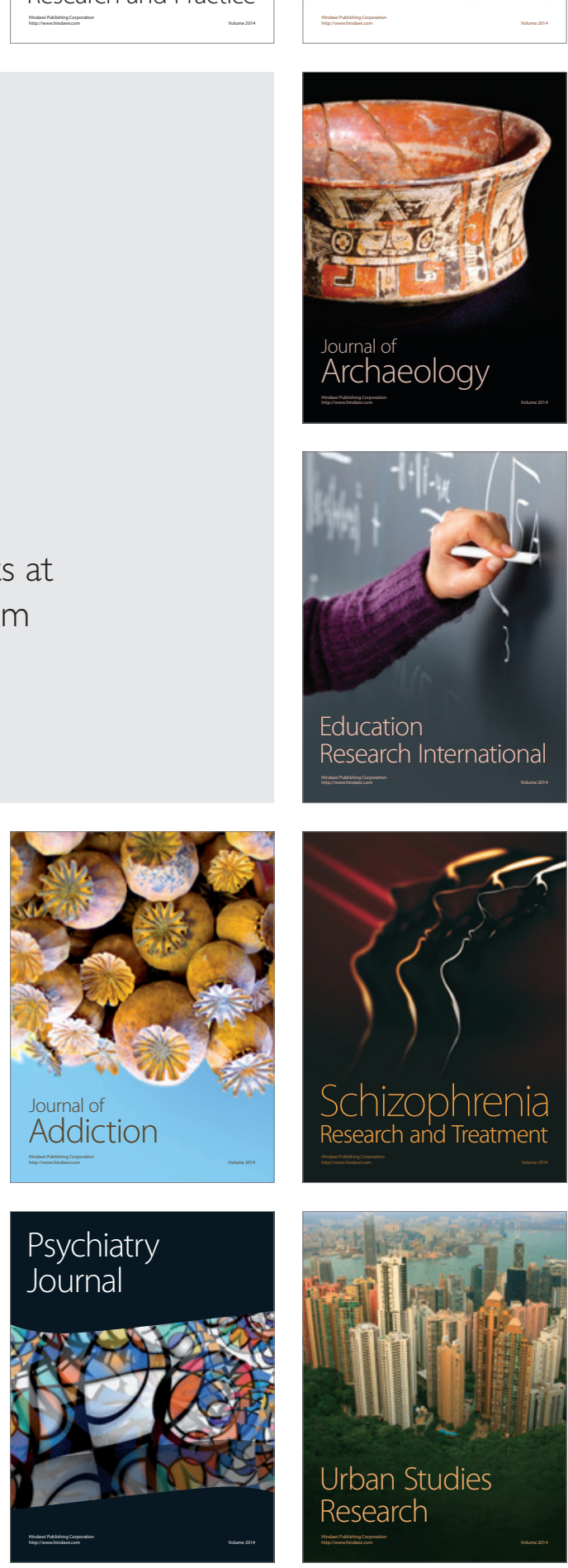